\title{
Em favor do conteúdo semântico das raízes
}

\author{
In favor of the semantic content of Roots \\ Rafael Dias Minussi* \\ Indaiá de Santana Bassani ${ }^{* *}$
}

\begin{abstract}
Resumo
O presente artigo tem como objetivo defender a presença de um conteúdo semântico conceitual nas raízes. São dois os argumentos presentes em Harley (2014) contra a individualização das raízes por meio da semântica na Lista 1: (i) a dificuldade de encontrar uma semântica comum em algumas palavras do hebraico formadas por uma mesma raiz e (ii) a existência de algumas raízes como, por exemplo, -ceive (de deceive e receive) e gred- (de regredir e progredir), que podem ser formalmente identificáveis, mas são aparentemente destituídas de significado fora de seu contexto morfossintático. Argumentamos que as conclusões de Harley se baseiam em pressupostos equivocados, uma vez que: (i) nem todas as palavras da língua hebraica são formadas por meio de raízes: há palavras formadas a partir de outras palavras, em que a identificação de uma raiz nos moldes do sistema tri-consonantal é impossível e, (ii) em relação às bases presas, a identidade formal não garante que se trate de fato da mesma raiz, pois a opção de reanálise não é considerada e, além disso, é possível identificar uma semântica comum para alguns subparadigmas. A partir dessa perspectiva, os exemplos de Harley deixam de servir como argumentos contra a presença de conteúdo semântico nas raízes na Lista 1.
\end{abstract}

Palavras-chave: raízes, semântica, morfologia distribuída.

\footnotetext{
${ }^{\star}$ UNIFESP

${ }^{\star \star}$ UNIFESP
} 
R. D. Minussi

$\&$ I. S. BASSANI Em favor do conteúdo semântico das raizes

\begin{abstract}
This paper aims at defending the presence of a conceptual semantics content in roots. Harley (2014) presents two arguments against the individualization of roots by their semantics in List 1: (i) the fact that it is difficult to find a common shared meaning in some hebrew words formed by the same root and (ii) the existence of roots like-ceive (as in deceive and receive) and gred- (in regredir and progredir), which are formally identifiable but apparently meaningless out of a morphosyntactic context. We argue that Harley's conclusions are based on wrong assumptions, since: (i) not all hebrew words are root derived: there are words derived from words in which the identification of a root from the tri-consonantal system is impossible and, (ii) in relation to bound roots, the formal identity does not guarantee that the forms share the same root, since the reanalysis option is not attempted and, besides of that, it is possible to identify a common meaning for some subparadigms. From this perspective, Harleys' examples are not arguments against the presence of semantic content in the roots of List 1.
\end{abstract}

Key-words: roots, semantics, distributed morphology. 


\section{Introdução}

s raízes, um dos mais importantes primitivos teóricos propostos
pela Morfologia Distribuída (MD), são alvo de controvérsias dentro
do próprio modelo por apresentarem, ou não, três propriedades fundamentais: (i) conteúdo fonológico, (ii) projeção de estrutura argumental e (iii) conteúdo semântico. Autores se dividem ao defenderem ou negarem a presença de conteúdo fonológico nas raízes (cf. BORER, 2003, 2013; ROCHA, 2008; PFAU, 2009); outros discordam sobre o fato de as raízes serem capazes de selecionar e/ou projetar argumentos, em especial o argumento interno (cf. ALEXIADOU, 2014; BASSANI; MINUSSI, 2015; BORER, 2013; HARLEY, 2014), e também há divergência a respeito da existência e do tipo de conteúdo semântico que podem abrigar (cf. ARAD, 2003, 2005; HARLEY, 2014).

$O$ debate envolvendo o modo de individualização das raízes é extremamente atual e polêmico, tendo merecido uma edição inteira da revista Theoretical Linguistics sob a forma de publicação do texto On the identity of roots ${ }^{1}$ (HARLEY, 2014) e de comentários e debates acerca do mesmo. Inserido neste debate, o presente artigo aborda a última questão mencionada: há possibilidade de individualização das raízes por meio de sua semântica? Mais especificamente, debateremos os principais argumentos em favor e contra a assunção de que as 1 Sobre a identidade das raízes (tradução nossa). Indicamos a leitura de Nóbrega (2015), que apresenta uma resenha de Harley (2014). 
R. D. Minussi

$\&$ I. S. BASSANI Em favor do conteúdo semântico das raizes raízes possuem semântica conceitual nuclear previamente a sua inserção em um contexto morfossintático. Defenderemos que não há argumentos suficientes para descartar a individualização das raízes por meio de sua semântica conceitual. A fim de melhor contextualizar o objetivo do trabalho, apresentaremos muito brevemente alguns pressupostos do modelo em que a discussão se dá.

A MD é uma teoria não lexicalista, cujo principal pressuposto é o de que tanto palavras quanto sentenças são formadas durante a derivação sintática. Sendo assim, não há um léxico gerativo e a sintaxe é alimentada por elementos primitivos contidos na Lista 1. A arquitetura da gramática pela MD pode ser vista na figura 1 (BASSANI; MINUSSI, 2015, p. 139). A Lista 1, abaixo, é um repositório de raízes e traços morfossintáticos; a Lista 2, também chamada de Vocabulário, contém regras de inserção de vocabulário e a Lista 3, chamada de Enciclopédia, contém conhecimento extralinguístico que atua na interpretação das raízes em contextos morfossintáticos. Ainda na Figura 1, podemos notar uma bifurcação ao fim da derivação sintática, cujo resultado é enviado para a Forma Lógica (LF) e para a Forma Fonológica (PF). No chamado caminho para PF, operações morfológicas como fusão, fissão e empobrecimento podem ocorrer antes da Inserção de Vocabulário. ${ }^{2}$

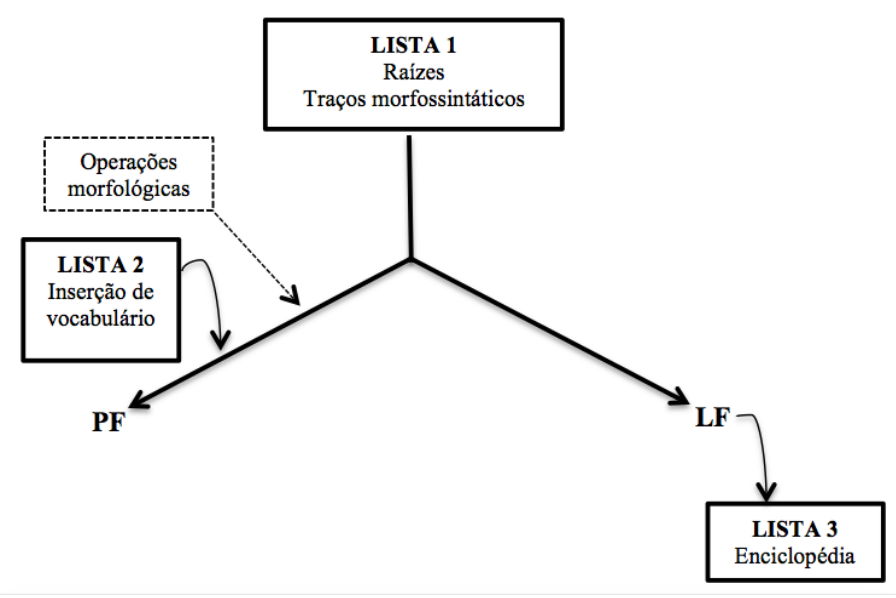

Figura 1. Arquitetura da Gramática proposta pela MD

Em recente artigo sobre as raízes, ao tratar do item (ii) acima, Bassani e Minussi (2015) defenderam que as raízes não selecionam o argumento interno, nem quando formam nomes, nem quando formam verbos. Os autores argumentam em favor desse fato através de dados de nominalizações do hebraico, dados de verbos complexos do português brasileiro (PB), além de dados de palavras complexas em diversas línguas, os quais mostram que os núcleos funcionais, fonologicamente realizados como padrões vocálicos (hebraico), prefixos (português) e partículas (outras línguas), são os responsáveis por licenciar o argumento interno. A argumentação vai contra a proposta de Harley (2014), a qual defende que as raízes podem selecionar e se concatenar diretamente a argumentos internos, configurando-se como um novo lexicalismo. No presente

2 Para mais detalhes sobre o modelo da Morfologia Distribuída, ver Scher, Bassani e Minussi (2013) e referências ali citadas.
Revista Letras,

Curitiba, UFPR, n. 96, pp.152-173, jul./dez. 2017 ISSN 2236-0999 (versão eletrônica) 
artigo, continuaremos a discussão acerca das propriedades de individualização das raízes, iniciada em Bassani e Minussi (2015) com enfoque nas questões acerca da semântica conceitual, como dissemos anteriormente.

Harley (2014) afirma que em nós terminais de raízes a interpretação semântica não é identificável antes de sua ocorrência em um contexto morfossintático derivado (p. 238) e oferece dois tipos de evidências para tal hipótese. O primeiro consiste em raízes consonantais de verbos do hebraico e o segundo em bases presas, especialmente do inglês.

Nosso objetivo principal é rediscutir os conjuntos de dados apresentados mostrando que é possível e mais interessante uma análise alternativa em que esses não se apresentam como evidência cabal para a afirmação de que as raízes não possuem informação semântica previamente à sua inserção na derivação sintática. O artigo se organiza do seguinte modo: na seção 2 , há uma breve introdução a dois tipos de semântica caros à teoria; na seção 3, são apresentadas as evidências favoráveis para a hipótese de que as raízes possuem conteúdo semântico, na seção 4, apresentamos as conclusões do trabalho seguidas de referências bibliográficas.

\section{As semânticas da raiz}

O foco do presente trabalho é o conteúdo conceitual das raízes, como já dissemos. No entanto, é importante explicitar que existem pelo menos dois tipos de conteúdo semântico em discussão desde os primeiros trabalhos em MD. Um tipo de conteúdo remete a uma semântica de eventos, cujo estudo resultou em uma tipologia de raízes, que podem ser classificadas em raízes de eventos causativos (cause), eventos de mudança de estado (become) e eventos estativos (state), além de raízes que denotam entidades (entity) e, portanto, não são eventivas. O outro tipo de conteúdo remete a um conceito geral, o qual estará presente nas palavras derivadas a partir de uma mesma raiz.

A respeito das tipologias para as raízes, Marantz (1997), um dos textos fundadores da MD, ao argumentar a favor de que nem todas as nominalizações precisam conter um $v$, ou seja, há nominalizações que de fato nunca são verbos em nenhum estágio da derivação, recorre a uma tipologia de raízes, baseada no trabalho de Levin e Rappaport Hovav (1995), o qual separa as raízes em mudança de estado externamente causada, mudança de estado internamente causada e raízes de resultado. Por essa tipologia, já está claro que, para este autor, as raízes não podem ser desprovidas de informação semântica que restringe o tipo de categorizador a que poderá se ligar.

Também Harley (1995) apresenta uma tipologia de raízes. Para a autora, as raízes podem ser de três tipos: (i) raízes que denotam entidades, (ii) raízes que denotam estados e (iii) raízes que denotam eventos, como podemos ver abaixo: 
R. D. Minussi

$\&$ I. S. BASSANI Em favor do conteúdo semântico das raízes

1. tipos de raízes

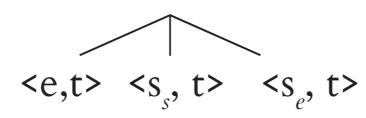

Marantz e Harley, portanto, argumentam para tipologias de raízes em uma abordagem para descrição de eventos. O primeiro tem como foco a separação das raízes de estado vs. de causa. A segunda está preocupada com raízes de modo geral, incluindo aquelas que denotam entidades. O nosso intuito ao trazer esse tipo de estudo para a semântica das raízes é mostrar que essa discussão abrange muito mais que apenas o conteúdo semântico/conceitual. Nas próximas seções, descreveremos o conteúdo conceitual das raízes e defenderemos que tal conteúdo está presente nas raízes na Lista 1.

\subsection{A semântica conceitual das raízes}

Segundo Arad (2005), a maioria das raízes do hebraico contém três consoantes, aqui representadas como $\sqrt{ } \mathrm{CCC}$, a partir das quais se podem criar nomes, verbos e adjetivos. Essas raízes adquirem numerosas interpretações quando são combinadas com diferentes padrões nominais, verbais e adjetivais, isto é, à medida que as raízes acategoriais são categorizadas pelos padrões vocálicos, elas adquirem um significado. Vejamos o exemplo da raiz $\sqrt{ }$ xšb (ARAD, 2005, p.16):

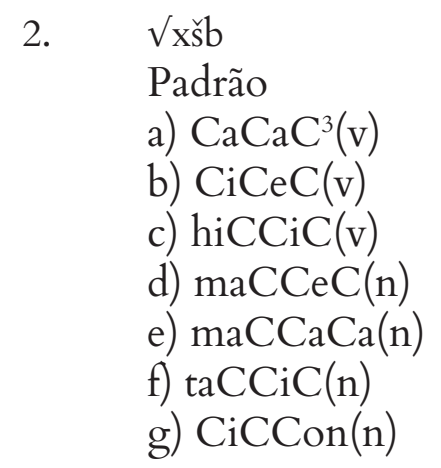

Palavra formada
xašav 'pensar'
xišev 'calcular'
hexšiv 'considerar'
maxšev 'computador'
maxšava 'pensamento'
taxšiv 'cálculo'
xešbon 'conta'

Os dados do hebraico nos ajudam a fazer uma diferença crucial entre o que estamos considerando como conceito, ou seja, um cerne semântico geral, o qual está presente nas raízes (no caso do hebraico, nas raízes tri-consonantais) e o que estamos considerando como significado: o resultado semântico da combinação de raiz e categorizador, o que, no caso do hebraico, é o resultado da combinação entre as raízes consonantais, as quais possuem um conceito geral, e os padrões vocálicos ${ }^{4}$.

$3 \mathrm{~A}$ letra $\mathrm{C}$ corresponde ao lugar que será ocupado por uma consoante da raiz.

4 Não nos alongaremos na discussão sobre a distinção entre conceito e significado dentro da teoria, uma vez que ela pode ser encontrada em trabalhos como o de Arad (2005), Minussi $(2008,2009)$.
Revista Letras,

Curitiba, UfPr, n. 96, pp.152-173, jul./dez. 2017 ISSN 2236-0999 (versão eletrônica) 
A relação semântica entre os significados das palavras formadas a partir de uma raiz pode ser bastante tênue. No caso das palavras acima, podemos sugerir, como conceito comum a elas, algo como atividade mental, que também pode ser realizada pelo computador, se entendermos que ele está pensando, ou processando, em nosso lugar.

Ainda vale ressaltar que nomes e verbos não são criados apenas a partir de raízes, mas também podem ser derivados de palavras que existem independentemente. Bat El (1994) explica que existem dois subgrupos de verbos formados a partir de palavras em hebraico: (i) os que são derivados de nomes e (ii) os que são emprestados de línguas estrangeiras. Os verbos desses grupos carregam similaridades com o nome ou radical do qual são derivados. Por exemplo, prefixos tais como $m$ - ou $t$-, que aparecem nos nomes, também aparecem nos verbos denominais, como está ilustrado pelos exemplos em (3)a-b). A forma dos verbos derivados tende a aparecer no padrão que melhor preserva a forma do nome, como no exemplo em (3)c), em que a palavra qliq, por já conter a vogal $i$, recebe um padrão que contenha uma vogal idêntica. Finalmente, o conjunto de consoantes da base é transferido como um todo para o verbo denominal (3)d-e).

3. Nome Base
a) taqciv (orçamento)
b) maxšev (computador)
c) qliq (click)
d) transfer (transfer)
e) striptiz (striptease)

\author{
Verbo formado \\ tiqcev (orçar) \\ mixšev (computadorizar) \\ hiqliq (clicar) \\ trinsfer (transferir, ${ }^{\star}$ tirnsfer) \\ striptez (striptease, ${ }^{\star}$ stirptez)
}

Uma vez que o significado final da palavra é composto por padrões e raízes, e que, para Arad (2005), os padrões servem a dois propósitos: (i) eles tornam pronunciáveis as consoantes impronunciáveis das raízes, e (ii) fornecem um traço de categoria, transformando a raiz acategorial em, por exemplo, um verbo, com uma interpretação específica, a pergunta natural é: qual a contribuição das raízes? ${ }^{55}$

Comecemos nossa reflexão dizendo que a maior parte das raízes pode aparecer em mais de um binyan. Uma vez que as raízes podem entrar em diversos contextos verbais, além de outros contextos categoriais, elas adquirem significados diversos, como já vimos em (2). A esse fenômeno, em que uma raiz adquire novos significados, mas mantém um cerne semântico na nova palavra formada, Arad (2005) chamou de Multiple Contextualized Meaning (MCM). No caso dos padrões verbais, uma mesma raiz cria dois, ou mais, verbos diferentes

5 Essa pergunta também deve estar na agenda dos trabalhos que tomam como pressuposto a MD e, diferentemente deste trabalho, assumem que raízes são elementos vazios (índices, por exemplo), pois se não há semântica conceitual nas raízes, essas não se diferenciam de morfemas funcionais. Logo, não haveria necessidade de propor dois tipos de primitivos: raízes/morfemas lexicais e morfemas abstratos funcionais, todos seriam morfemas abstratos. Uma breve discussão contra a ideia de índices e sobre a diferença entre raízes e morfemas funcionais pode ser encontrada em Rappaport Hovav (2014). 
R. D. Minussi

$\&$ I. S. BASSANI Em favor do conteúdo semântico das raizes quando é inserida em dois, ou mais, binyanim, como podemos ver nos exemplos em (4) e (5):

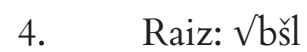

a) P3 bisel (cozinhar)

b) P5 hivšil (amadurecer)

$\begin{array}{llll}\text { 5. Raiz: } \sqrt{ } \text { btx } & \text { a) } & \text { P1 } & \text { batax } \\ & \text { b) } & \text { P3 } & \text { biteax } \\ & \text { c) } & \text { P5segurar) } & \text { hivtiax } \\ & \text { (prometer/garantir) }\end{array}$

Nos exemplos acima, os verbos criados a partir de raízes que apresentam o fenômeno de MCM estão nos padrões 1, 3 e $5^{6}$. Como a autora nota, esses são precisamente os padrões que não possuem qualquer restrição de transitividade sobre os verbos que são formados, além de serem os padrões que podem apenas originar verbos derivados de raiz e não verbos derivados de nomes ou adjetivos.

O fato de uma raiz não poder aparecer em qualquer padrão mostra que deve existir uma restrição ligada à alguma propriedade da raiz em combinação com as propriedades transitivas ou intransitivas dos padrões.

Nesse ponto, Arad começa a argumentar em favor do fato de que o sistema de padrões verbais hebraicos se caracteriza por certa regularidade e irregularidade. A regularidade é dada por meio das alternâncias, uma vez que tais alternâncias costumam aparecer regularmente em certos padrões. A irregularidade é devida à MCM, em que uma mesma raiz, se alocada em diferentes padrões, pode possuir significados diferentes e arbitrários. Se há irregularidades no sistema de padrões do hebraico, é natural que alguns significados negociados após a combinação entre a raiz e o padrão possam ser distantes do conceito presente nas raízes.

Há uma previsão de que se uma única raiz aparecer em cinco ou mais binyanim, pelo menos alguns desses serão instâncias de MCM. No exemplo abaixo, podemos ver que em (6)a-c-e temos MCM e, em (6)b-d-f $\mathrm{f}^{7}$, temos alternâncias:

6 Os padrões são templates que combinam vogais e espaços reservados às consoantes. O hebraico possui sete padrões vocálicos verbais e um número maior de padrões nominais. Cada padrão transitivo/causativo possui um correspondente incoativo ou um padrão de voz passiva correspondente. O P1 possui como voz passiva o $\mathrm{P} 2$, o $\mathrm{P} 3$ tem sua voz passiva formada por meio do P4 e o P5 forma a voz passiva ou a alternância incoativa com o P6. Desse modo, P1, P3 e P5 são padrões transitivos, enquanto P2, P4 e P6, podem ser considerados padrões intransitivos. Uma discussão sobre esses fatos pode ser encontrada em Doron (2003) e Arad (2005).

7 Retomando o que já iniciamos na nota 6, se alguns padrões são correspondentes a outros padrões e atuam modificando a estrutura de argumentos, por exemplo, P1 e P2, P3 e P4 e P5 e P6, é natural que o P2 tenha um significado próximo ao do P1 e o P4 tenha um significado próximo ao do $\mathrm{P} 3$, etc. Assim sendo, podemos notar as instâncias de MCM nos padrões ligados diretamente à raiz P1, P3 e P5, como já foi dito. O P7, no caso do exemplo em 6 (f) é considerado um padrão reflexivo e em alguns verbos está apenas ligado a questões de alternância, podendo apresentar ou não MCM.
Revista Letras,

Curitiba, UfPr, n. 96, pp.152-173, jul./dez. 2017 ISSN 2236-0999 (versão eletrônica) 
6. $\quad \sqrt{ } \mathrm{yd}$ ?

a) $\mathrm{CaCaC}$ yada? (saber)

b) niCCaC nodal (tornar sabido)

c) $\mathrm{CiCeC}$ yide?a (dar a conhecer)

d) $\mathrm{CuCaC} \quad$ yuda? (dar a conhecer-passivo)

e) hiCCiC hodi?a (informar)

f) hitCaCeC hitvadela (familiarizar-se com)

Para não cair num enfoque determinista ou não determinista, isto é, um enfoque que defende que os padrões vêm do léxico com determinadas características, de modo que são totalmente especializados em alternâncias (ou seja, são intrinsecamente causativos, reflexivos etc) ou são especializados na criação de novos verbos, ou ainda, que não há nada de regular nos padrões verbais, a autora começa por listar cada raiz de acordo com o padrão em que ela aparece, a fim de esquematizar uma categorização das raízes e mostrar sua relação com os padrões. Desse modo, um importante resultado advém dessa esquematização: a presença de uma mesma raiz em diferentes padrões é limitada, de modo que as raízes podem ser separadas em grupos bem definidos. Arad identifica cinco grupos de raízes, os quais serviram para uma análise quantitativa posterior. Um dos grupos encontrados pela autora diz respeito ao das raízes em 160 que o MCM pode ocorrer:

7. Rai
a) $\sqrt{b x n}$
b) $\sqrt{ } \times s ̌ b$
Verbo $_{1}$
Verbo $_{2}$
c) $\sqrt{ }$ grš
baxan (examinar, P1)
xašav (pensar, P1)
gereš (expelir, P3)
hivxin (discernir, P5)
xišev (calcular, P3)
hitgareš (divorciar-se, P7)

Para a autora, o sistema de padrões vocálicos possui lacunas, principalmente no que diz respeito à distribuição das raízes pelos padrões. Esse sistema de padrões reflete duas propriedades. A primeira é de que esse sistema não é determinístico. A contribuição dos binyanim não é semântica e sintaticamente transparente. Cabe à semântica de cada raiz licenciar a sua participação nas alternâncias de estrutura argumental ou na atribuição de um significado contextualizado múltiplo (MCM). A segunda propriedade é que o sistema é pobre: o hebraico trabalha com um pequeno número de verbos. Para cada raiz, há cinco possibilidades morfológicas verbais.

Uma das contribuições do trabalho de Arad (2005) para este trabalho, além de mostrar que a MCM é fator intrínseco ao sistema de formação de palavras do 
R. D. Minussi

$\&$ I. S. BASSANI Em favor do conteúdo semântico das raizes hebraico, reside em discutir que esse mesmo sistema de formação de palavras no hebraico não utiliza apenas raízes tri-consonantais, uma vez que esse recurso é limitado ${ }^{8}$. Isso nos leva a pensar que os contra exemplos trazidos por Harley (2014) para a existência de algum tipo de semântica nas raízes, na realidade, devem ser exemplos de palavras formadas não por raízes tri-consonantais. Discutiremos essa ideia em seguida.

\section{Revisitando os dados do hebraico}

Harley (2014) discute amplamente o modo de individualização das raízes na Lista 1. Inicialmente, questiona se as raízes devem ser individualizadas por meio do conteúdo fonológico 9 , chegando à conclusão de que esse critério de individualização não deve ser aceito. O principal argumento se baseia na existência de raízes supletivas, cuja forma é determinada por um contexto morfossintático específico. Isso a leva a concluir que as raízes não devem possuir um conteúdo fonológico e estão sujeitas à Inserção Tardia, assim como qualquer nó terminal ${ }^{10}$.

Seguindo a argumentação, a próxima questão tratada por Harley (2014) se refere à possibilidade de individualização das raízes na Lista 1 com base na informação semântica/conceitual. A autora defende que as raízes não podem ser individualizadas por meio dessa informação, pois há raízes cuja interpretação semântica nãoé identificável antes de sua inserção em um contexto morfossintático.

Harley (2014) toma o hebraico como exemplo, para mostrar que uma mesma raiz consonantal possui significados tão distantes que é difícil manter a ideia de que essa mesma raiz contenha alguma semântica primitiva. Para ilustrar este fato, podemos tomar o exemplo de Aronoff (2007) por meio da raiz $\sqrt{ } \mathrm{kb} \int$, a qual pode derivar as seguintes palavras:

\begin{tabular}{|c|c|c|}
\hline 8. & $\begin{array}{l}\text { a) kvis } \\
\text { b) kvisa } \\
\text { c) kavas } \\
\text { d) mexubaf }\end{array}$ & $\begin{array}{l}\text { 'estrada pavimentada' } \\
\text { 'compressão' } \\
\text { 'ocupado' } \\
\text { 'pressionado' }\end{array}$ \\
\hline
\end{tabular}

Percebemos que a gama de significados gerados por uma mesma raiz $\checkmark \mathrm{kb} \int$ é ampla, impossibilitando, segundo Harley, a delimitação de um conteúdo comum, o qual estaria contido na raiz. Para a autora, uma vez que precisamos

$8 \mathrm{O}$ fato de que nem todas as raízes ocorrem em todos os padrões nos leva a pensar que a inserção de uma raiz em determinados padrões é restrita por sua semântica. Essa ideia merece ser explorada em trabalhos futuros.

9 Abordaremos a questão do conteúdo fonológico das raízes em Bassani e Minussi (em preparação).

10 O principal argumento da autora provém da existência de raízes supletivas como, por exemplo, go e went. Não está no escopo deste trabalho a discussão sobre o conteúdo fonológico das raízes. Para maiores detalhes a respeito da Inserção Tardia de conteúdo fonológico nas raízes veja Rocha (2008), Minussi (2009), Pfau (2009) e Siddiqi (2009).
Revista Letras,

Curitiba, UfPr, n. 96, pp.152-173, jul./dez. 2017 ISSN 2236-0999 (versão eletrônica) 
tanto de contexto morfossintático para definir a fonologia de uma raiz quanto para definir sua interpretação, não podemos usar essas propriedades para a individualização. Em resumo, as raízes são morfemas abstratos, individualizados, mas não há uma raiz como $\sqrt{ }$ RUN, portadora de um conceito na Lista 1.

Defendemos a possibilidade de existência de um conteúdo conceitual nas raízes, com base na teoria de MCM de Arad (2005). Argumentamos que os contraexemplos em (8) trazidos por Harley (2014) são equivocados e estão baseados numa premissa errônea, de que as palavras do hebraico sempre são formadas exclusivamente a partir de raízes consonantais.

O primeiro argumento provém do trabalho de Pham (2011), que mostra que algumas palavras do hebraico também podem ser formadas a partir de palavras. O segundo argumento provém das possibilidades de análise da derivação da raiz $\sqrt{ } \mathrm{kb} \int$, conforme discutido por Rappaport Hovav (2014). Abordamos os dois argumentos na sequência do texto.

Assumimos, por meio do trabalho de Pham (2011), que novas palavras do hebraico podem ser formadas a partir de outras palavras e não apenas a partir de raízes consonantais. As evidências para esse fato provêm de blends ${ }^{11}$ na língua hebraica, os quais, como argumenta Pham (2011), não são formados a partir de raízes, mas a partir de palavras.

Segundo o autor, os blends são formados por duas palavras, em vez de serem formados por raízes na língua hebraica. A ideia de que os blends poderiam ser formados por raízes provém, naturalmente, do próprio sistema morfológico da língua. De acordo com o autor, se assumirmos que os blends são formados por duas raízes, temos a seguinte estrutura para um nome como daxpor 'escavadeira', descrito em (9) e representado estruturalmente em (10):

9.

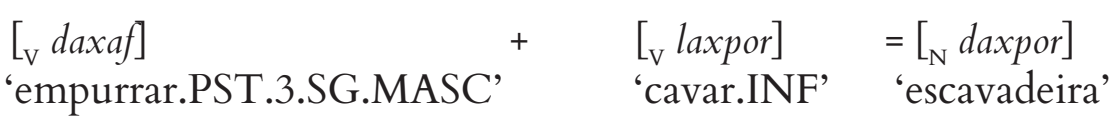

10.

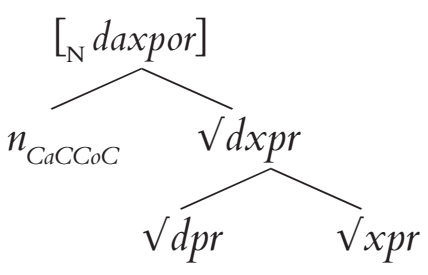

Podemos observar outros exemplos de blends no hebraico como aquele apresentado em (10), elencados em (11).

11 Sobre diferentes definições de blends e a apresentação da derivação completa desses elementos, veja os trabalhos de Minussi e Nóbrega (2014) e Nóbrega e Minussi (2015). 
R. D. Minussi

\& I. S. BASSANI Em favor do conteúdo semântico das raizes
11.
a) $[$ šmanman $]+$
'roliço/cheio'
b) $\left[{ }_{N}\right.$ pri $\quad+$ 'fruta'
c) $\left[{ }_{N} c f a r d e ? a\right]+$

$[$, namux

'curto'

$\left[{ }_{N}\right.$ yogurt $]$

'iogurte'

$\left[{ }_{\mathrm{N}} x \operatorname{argo}\right.$

'gafanhoto'
[

'atarracado'

[ ${ }_{\mathrm{N}}$ prigurt $]$

'iogurte de fruta' (marca)

$\left[_{\mathrm{N}}\right.$ cfargol $]$

'alfinete em forma de rã ou gafanhoto'

(PHAM, 2011, p. 17)

Se tomarmos, por exemplo, o nome prigurt 'marca de iogurte de fruta' em (11)a) e avaliarmos a hipótese de formação do blend a partir de uma única raiz, teremos de assumir uma raiz composta apenas por 5 consoantes como $\sqrt{ }$ prgrt. Entretanto, Pham (2011) elenca alguns possíveis problemas para essa análise. Em primeiro lugar, para que essa raiz se torne um nome é necessário que ela se concatene, na derivação sintática, a um categorizador $n$, realizado em hebraico por um mišqal (cf. MINUSSI, 2012), isto é, um padrão vocálico nominal, como miCCeCet, o qual forma a palavra misgeret 'quadro/moldura' a partir da raiz $\sqrt{s g r}$. Assumindo que podemos tomar um mesmo padrão vocálico para formar outros nomes, esperaríamos que fosse possível formar um nome utilizando a raiz $\sqrt{ }$ prgrt mais um padrão vocálico da língua como miCCeCet, por exemplo, * mipregert. Contudo, como foi observado por Pham (2011), a concatenação dessa e de outras raízes de blends a padrões nominais existentes na língua é impossível.

Em segundo lugar, temos, como consequência da análise de blends formados a partir de raízes, a previsão da existência de um número vasto de mišqalim - padrões vocálicos nominais -, isto é, um novo padrão nominal para cada nova raiz extraída de um blend. Tomando, por exemplo, o blend demoktator 'um democrata que se comporta como um ditador' em (12), preveríamos, segundo Pham (2011), que tal blend é formado por uma raiz $\sqrt{ } d m k t t r$ e necessitaria se concatenar com um núcleo definidor de categoria $n$ que é realizado pelo mišqal CeCoCCaCoC. Para o autor, essa é uma análise indesejável, pois criaria um padrão vocálico exclusivo a essa raiz.

12

\begin{tabular}{|c|c|c|c|c|}
\hline$\left[{ }_{N}\right.$ demokrat $]$ & + & {$\left[_{\mathrm{N}}\right.$ diktator $]$} & $=$ & {$\left[{ }_{\mathrm{N}}\right.$ demoktator $]$} \\
\hline 'democrata' & & 'ditador' & & $\begin{array}{l}\text { 'democrata que se comporta } \\
\text { como um ditador' }\end{array}$ \\
\hline
\end{tabular}

Em terceiro lugar, os blends são formados por palavras flexionadas. O prefixo mit-, no exemplo em (13), pertencente ao padrão vocálico verbal hiCaCCeC, permanece no blend após a mesclagem, apesar de o blend formado não ter relação morfológica com o padrão vocálico verbal das palavras-fonte. Observando o exemplo, podemos analisar o prefixo como parte da primeira palavra-fonte: 
13.

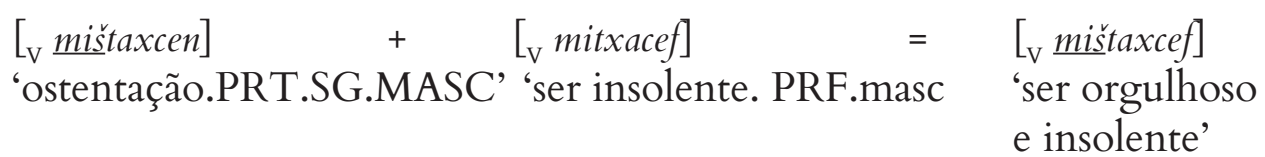

Em resumo, podemos concluir que os blends no hebraico não são formados a partir de uma única raiz, tal como vimos em (9), tampouco pela mescla de duas raízes na sintaxe, como visto em (12), por meio dos argumentos trazidos por Pham (2011).

Voltando à discussão colocada por Harley (2014) para os dados do hebraico, após mostrar que as palavras do hebraico nem sempre são formadas por raízes consonantais, temos, portanto, maior embasamento para dizer que os dados em (8) podem não ser formados por uma mesma raiz. Desse modo, a derivação dessas palavras seguiria os moldes das derivações de palavras simples em línguas não-templáticas, ou seja, no caso de (8)a. sugere-se a seguinte estrutura: [[ $\sqrt{ } \mathrm{kvi} j]$ $\varnothing]_{\mathrm{n}}$, em que $n$ não se refere a um padrão vocálico, mas a um nominalizador foneticamente nulo. Se assumirmos, como pressuposto, como parece ser feito por Harley (2014), que todas as palavras do hebraico são formadas por raízes consonantais, não conseguiremos explicar os dados dos blends corretamente, seja para o hebraico ou para qualquer outra língua. O fato é que, para os dados em (8), assim como para os blends, não é possível assumir um padrão vocálico para a formação dessas palavras.

Rappaport Hovav (2014) também discute os mesmos dados trazidos por Aronoff (2007) e defende que não há propriedades estruturais que possam determinar que aquelas palavras sejam todas construídas a partir de uma mesma raiz. A autora diz que não há propriedades de alternância morfofonológica ou padrão verbal associado com os verbos também formados com a raiz $\sqrt{ } \mathrm{kb} \int$ que determinarão que as formas kava (ocupado) e kvif (estrada pavimentada) sejam de qualquer modo relacionadas. Se olharmos com mais atenção para os padrões nominais dessas palavras perceberemos que kavas no sentido de "pegar" tem como correspondente o nominal derivado kvi a, mas kavas no sentido de "ocupar" tem um nominal derivado imprevisível $k i b u \int^{12}$. Desse modo, a autora mostra que não há nenhuma propriedade estrutural comum entre o nominal kvið e algum outro verbo do qual possa ter sido derivado.

\subsection{Revisitando os dados com bases presas}

O segundo conjunto de contraexemplos à individualização semântica das raízes são casos do inglês, análogos aos do hebraico, e que também existem em línguas como o português e em diversas outras línguas. Há algumas raízes que podem ser formalmente identificadas, mas que são aparentemente destituídas

12 Para uma discussão mais aprofundada sobre as correspondências entre os padrões nominais e verbais e a imprevisibilidade de alguns padrões nominais ver Minussi (2012). 
R. D. Minussi

$\&$ I. S. BASSANI Em favor do conteúdo semântico das raizes de significado fora de seu contexto morfossintático. Na literatura morfológica tradicional são conhecidos como casos de palavras formadas por bases presas. Vejamos alguns exemplos:

14.
a) -ceive deceive 'enganar', receive 'receber', conceive 'conceber', perceive 'perceber'
b) -port
comport 'comportar', deport 'deportar', report 'reportar', import 'im- portar', support 'suportar'.
c) -gre(d)
agredir, regredir, progredir, transgredir

Harley ressalta que, além da identidade fonológica, esses itens sofrem alomorfias contextuais e impõem restrições em relação aos sufixos que os acompanham. Por isso, devem ser isolados como raízes do inglês:

15.
a) -ceive $\rightarrow$-cept +ion
deception 'decepção', reception 'recepção', conception 'concepção', perception 'percepção'.
b) -pose $\rightarrow$-pos +ition ( não -ation ou -ion) composition 'composição', supposition 'suposição', proposition 'pro- posição', deposition 'deposição'

Segundo a argumentação, essa alomorfia pode ser mais bem explicada se assumirmos que essas palavras provêm da mesma raiz, ou a relação entre o contexto de ocorrência das alomorfias e as palavras se tornaria um mistério.

- Raízes como -ceive (receive, deceive, etc.) e gre(d)- (agredir, progredir, regredir) ainda possuem algum conteúdo semântico identificável pelos falantes?

Harley argumenta que raízes do inglês tradicionalmente classificadas como bases presas (ARONOFF, 1976), tais como -ceive, -here, -port, -pose, em diferentes contextos morfossintáticos, possuem a mesma identidade fonológica, sofrem as mesmas alomorfias contextuais, impõem restrições em relação aos sufixos que as acompanham, mas não é possível delimitar-lhes um conteúdo semântico comum. Tais fatos seriam também evidências para assumir que essas raízes não podem ser individualizadas por seu conteúdo semântico, ou seja, não possuem especificação semântica antes de sua inserção em um contexto morfossintático. Apesar disso, esses mesmos fatos são colocados como evidências em favor da assunção de que todas as palavras derivadas de uma mesma forma presa são possuidoras da mesma raiz. A partir disso, exploramos duas questões relativas à proposta de análise para as formas presas, em face de dados adicionais:

Revista Letras,

Curitiba, UFPR, n. 96, pp.152-173, jul./dez. 2017 ISSN 2236-0999 (versão eletrônica) 
i. Seriam essas raízes de fato as mesmas em todos os contextos?

ii. Não é de fato possível isolar uma semântica nuclear mínima para alguns paradigmas?

Segundo a linha de argumentação de Harley, devemos considerar que a raiz de todas as formas em (16) abaixo é -gre(d), dado que todas selecionam a mesma vogal temática $(-i-)$ e, logo, o mesmo particípio (agredido, progredido, regredido, transgredido), além do mesmo sufixo nominalizador (agressão, progressão, regressão, transgressão). Porém, não é de se esperar que seja possível isolar uma contribuição semântica comum a -gre(d).

16.
a) agredir
b) progredir
c) regredir
d) transgredir

No entanto, conforme observado em Bassani (2015), apesar de todos serem formalmente iguais, o que vai ao encontro da análise de Harley, somente regredir e progredir (talvez transgredir) formam um paradigma semântico (possivelmente) analisável sincronicamente por linguistas e falantes, dada a oposição oriunda da presença dos prefixos e do que consideramos ser um conceito compartilhado e coerente proveniente da raiz, apesar de difícil definição e isolamento. Diferentemente, não é possível assumir sem problemas que a mesma análise pode ser estendida ao verbo agredir, em que a contribuição semântica do prefixo (relacionada a aproximação) é obliterada. Nesse caso, apesar da identidade fonológica, é mais plausível que tenha havido uma reanálise e que a raiz da forma agredir seja de fato -agre(d) ao passo que a raiz para regredir, progredir (talvez transgredir) seja -gre(d), separando-os em dois conjuntos de dados apenas diacronicamente relacionados.

O fato de os dois conjuntos de dados possuírem as mesmas seleções formais pode ser entendido de dois modos: primeiro, há um número finito de formas alomórficas do particípio e da nominalização, e o fato de esses itens terem identidade fonológica e selecionarem os mesmos sufixos pode ser aleatório ou pode ser que os sufixos sejam selecionados por default. Além disso, essa seleção pode ser um resquício histórico, que marcou tanto a raiz que permanece ativa quanto a raiz que foi reanalisada. Ademais, a questão parece ainda mais simples se entendermos que os sufixos mais externos, como os de particípio e de nominalização, podem ser de fato restringidos pela vogal temática e não pela raiz. Tais fatos não nos parecem cabais para assumir que todas as raízes do inventário das línguas naturais não possuem conteúdo semântico; ao contrário, nos parecem de fato insuficientes e menores.

A estreita relação entre forma dos afixos e identidade da raiz proposta por Harley é desafiada por evidências de outras línguas, como o espanhol e o 
R. D. Minussi

$\&$ I. S. BASSANI Em favor do conteúdo semântico das raizes

inglês. Fabregas et al. (2007) apresentam casos de perda de irregularidade na seleção dos sufixos no espanhol quando determinadas raízes fazem parte de estruturas maiores. Apesar de não assumirem que são casos de reanálise, os dados evidenciam que não é só a suposta raiz que determina a forma dos sufixos, e que a relação entre selecionar os mesmos afixos e ser a mesma raiz não é tão direta. Pelo raciocínio de Harley, temos de assumir que os dados apresentados por Fabregas et al. (2007), decir e contradecir por um lado, e bendecir e maldecir, por outro, contêm raízes diferentes, pois as duas primeiras formas tomam o particípio irregular e as duas últimas selecionam a forma regularizada. $\mathrm{E}$ o que dizer, então, em relação a desdecir e predecir, para os quais nenhuma das duas formas parece perfeita? Dizer que não são de fato a mesma raiz desafia enormemente a semântica minimamente compartilhada entre as formas. Aqui temos casos em que há identidade semântica, mas não há identidade formal.

17.
a) decir $\sim$ dicho $\sim$ *decido
b) contradecir $\sim$ contradicho $\sim{ }^{\star}$ contradecido
c) bendecir $\sim$ *bendicho $\sim$ bendecido
d) maldecir *maldicho $\sim$ maldecido
e) desdecir $\sim$ ? desdicho $\sim$ ? desdecido
f) predecir $\sim$ ? predicho $\sim$ ? predecido

Em outros casos, uma mudança na seleção alomórfica que faz a raiz ou na sua própria forma é claramente acompanhada ou causada por uma mudança semântica. Alguns exemplos de casos de regularização de formas irregulares no inglês são apontados por Pinker (1999). São casos em que a perda da identidade semântica leva à perda da identidade formal da raiz. Uma vez que há comprovação de perda de identidade semântica, devemos admitir que havia identidade semântica entre as raízes. Pinker (p.149) apresenta algumas formas em contextos de expressões maiores:

18.
a) life $\sim$ lives
b) All my daughter's friends are lowlifes.

19.
a) mouse $\sim$ mice
b) I am sick with dealing with all the Mickey Mouses in this administration.

20.
a) stick stuck
b) He high-sticked his opponent.

Nas formas em a. de (18) e (19), são apresentados os plurais dos nomes life ('vida') e mouse ('rato'), que são, na língua padrão, irregulares: lives e mice e 
em (20)a. o passado para stick ('perfurar, furar') é stuck. Quando em estruturas compostas, com (alguma) perda de composicionalidade, em low-lifes ('desonestos, criminosos') e Mickey Mouse (o personagem de Walt Disney), ocorre a regularização. $\mathrm{O}$ mesmo se dá em high-stick (termo utilizado no hóquei para situações em que um jogador joga com o taco acima do ombro, com possibilidade de atingir alguém), que passa a ser conjugado como high-sticked. Se a perda da identidade formal deriva da perda da identidade semântica, havia identidade semântica. Outros casos parecidos ocorrem com o plural mouses para mouse de computador e o passado grandstanded para grandstand (ostentar uma performance para impressionar uma audiência), em vez de ${ }^{*}$ grandstood, analogamente ao que ocorre no verbo stand stood ('ficar em pé, aguentar').

A constatação que se coloca, frente aos dados do tipo de (18) a (20), é a seguinte: se a argumentação de Harley vai em favor da identidade formal entre raízes com base na seleção idêntica de alomorfes sufixais e ocorrências de alomorfias de raiz, e assume que não existe nenhuma identidade semântica prévia à inserção sintática, como seria explicada, na análise da autora, as consequências para escolhas formais, como conjugação (irregular ou regular) e alomorfias, causadas pela perda (ou enfraquecimento) da identidade semântica?

Além disso, dados em que há variação na forma do afixo escolhido pelo falante mostram que a falta de identidade formal também não indica necessariamente a falta de identidade semântica. As seguintes formas do português padrão e do português popular (ou informal), respectivamente, são exemplos de variação alomórfica para uma mesma raiz:

Para responder às questões levantadas em i. e ii., então, é preciso levar em conta que para muitos casos em que se argumenta não haver mais uma semântica comum, o que não há de fato são raízes comuns, mas raízes diferentes já incorporadas na forma que aparentemente é complexa: eram a mesma raiz, não são mais, então não faz sentido buscar semântica comum nessas raízes. Esse modo de ver o problema pode anular o argumento de Harley. A autora não considera que na atualidade as estruturas complexas podem ser reanalisadas como simples, o que gera a nova raiz. Evidências surgem no fato de que os falantes já não reconhecem mais a sua complexidade e de que padrões morfológicos são alterados, padrões morfológicos que são determinados pela raiz e que são diferentes daqueles que são selecionados pelas supostas raízes idênticas.

Em face de dados como os apresentados acima, em especial o paradigma que contém a forma -gre(d)-, e o de -tra- apresentado abaixo, assumimos que é possível sim encontrar uma semântica comum com base no reconhecimento 
R. D. Minussi

$\&$ I. S. BASSANI Em favor do conteúdo semântico das raizes de estruturas morfológicas complexas (com presença de potenciais prefixos e sufixos). A raiz -tra- em (23) é analisável por falantes e linguistas e pode ser identificada por uma semântica que contém a ideia de movimento. $\mathrm{O}$ mesmo não é mais tão evidente em distrair.

23.
a) atrair
b) contrair
c) retrair
d) extrair
e) subtrair

Concluir que não há semântica em -tra- pela observação de todo o paradigma é incorreto. Nesse caso, não é possível identificar a semântica comum para o paradigma todo, mas é possível identificar para um subparadigma, em que a raiz ainda é a mesma, pois não foi reanalisada ${ }^{13}$.

\section{Conclusões}

A observação cuidadosa dos dados nos leva a concluir que as evidências apresentadas para a afirmação de que as raízes não podem ser individualizadas na Lista 1 por meio do seu conteúdo semântico não são, na verdade, robustas. Isto porque: (i) os dados do hebraico utilizados para mostrar a dificuldade em se obter uma semântica comum podem ser descritos e analisados como não formados a partir de uma raiz comum, ou mesmo de uma raiz, por exemplo: o nominal kvi "estrada pavimentada" não se relaciona estruturalmente com nenhum outro nominal supostamente derivado da mesma raiz, o que indica que tal nominal não é formado pela mesma raiz; (ii) o fato de um conjunto de dados apresentar identidade formal e não apresentar identidade semântica não significa que se trata necessariamente de um conjunto de dados formado da mesma raiz, como vimos com as formas agredir e regredir/progredir. Apesar de historicamente derivadas da mesma raiz, deve-se considerar a possibilidade de reanálise da raiz na primeira palavra, já que este dado se distancia dos demais do paradigma em um exercício de comutação.

A partir de tais constatações, observamos que a autora usa conjuntos de dados excepcionais para propor mudanças sistemáticas na arquitetura da gramática e nos primitivos da teoria. Dois aspectos de natureza diversa são tratados da mesma forma dentro do modelo de Harley (2014); são eles: a relevância de traços semânticos durante a derivação sintática e a individualização das raízes por meio de conteúdo semântico na Lista 1. Considerar que a raiz pode ser individualizada pelo conteúdo conceitual não significa admitir, necessariamente, que a

13 Conforme aponta um dos pareceristas anônimos, a realização de experimentos pode ajudar a corroborar ou refutar tais hipóteses de decomposição morfológica e identidade semântica em subparadigmas. Esperamos contemplar tal estudo em trabalho futuro.
Revista Letras,

Curitiba, UFPR, n. 96, pp.152-173, jul./dez. 2017 ISSN 2236-0999 (versão eletrônica) 
computação sintática precise manipular ou ter acesso a esse tipo de informação semântica.

Por fim, não considerar que há algum tipo de semântica que individualize as raízes já na Lista 1 pode trazer duas consequências importantes: (i) a perda da possibilidade de explorar teórica e empiricamente as restrições que a semântica pode impor sobre as raízes, uma vez que há algum grau de restrição de cunho semântico sobre o contexto morfossintático em que uma raiz pode ocorrer; (ii) a retirada do conteúdo conceitual da Lista 1 tal como é feito no modelo proposto implica em somente realocá-lo em outro lugar da gramática, nesse caso, a Lista 3 , que é sobrecarregada com regras de correspondência. 
R. D. MinusSi

\& I. S. BASSANI Em favor do conteúdo semântico das raízes

\section{Bibliografia}

ALEXIADOU, ARTEMIS. Roots don't take complements. Theoretical Linguistics, v. 40, n.3/4, p. 287-297, 2014.

ARAD, MAYA. Locality constraints on the interpretation of roots: the case of Hebrew denominal verbs. Natural Language \& Linguistic Theory, v. 21, p. 737778, 2003.

ARAD, MAYA. Roots and Patterns: Hebrew morpho-syntax. Dordrecht: Springer, 2005.

ARONOFF, MARK. In the beginning was the Word. Language, v. 83, n.4, p.803-830, 2007.

ARONOFF, MARK. Word Formation in Generative Grammar. Cambridge: MIT Press, 1976.

BASSANI, INDAIÁ DE SANTANA. Transparência morfológica, composicionalidade semântica e reanálise estrutural em verbos do português. Revista Letras (Curitiba), v. 91, p. 109-130, 2015.

BASSANI, INDAIÁ DE SANTANA; MINUSSI, RAFAEL DIAS. Contra a seleção de argumentos pelas raízes: nominalizações e verbos complexos. ReVEL, v. 13, n. 24, p. 139-173, 2015.

BAT EL, OUTI. Stem modification and cluster transfer in Modern Hebrew, Natural Language, and Linguistic Theory, v. 12, p. 571-596, 1994.

BORER, H. Exo-skeletal vs. Endo-skeletal Explanations: Syntactic Projections and the Lexicon. In: POLINSKY, M.; MOORE, J. (Eds.) The Nature of Explanation. Chicago: Chicago University Press (distributed by CSLI), 2003. p. 1-35.

BORER, H. Structuring Sense Volume III: Taking Form. United Kingdom: Oxford University Press, 2013.

DORON, EDIT. Agency and Voice: The Semantics of the Semitic Templates. Natural Language Semantics, v. 11, p.1-67, 2003.

FABREGAS, ANTONIO; ARQUIOLA, ELENA FELÍU; VARELA, SOLEDAD. The Lexical Integrity Hypothesis and the Notion of Irregularity: The Case of Spanish Participles. In: G. Booij et al. (Eds.). On-line Proceedings of the Fifth Mediterranean Morphology Meeting (MMM5) Fréjus 15-18 September 2005, University of Bologna, 2007.

HARLEY, HEIDI. On the identity of roots. Theoretical Linguistics: An Open Peer Review Journal, v. 40, n. 3-4, p. 225-276, 2014.
Revista Letras,

Curitiba, UfPR, n. 96, pp.152-173, jul./dez. 2017 ISSN 2236-0999 (versão eletrônica) 
Subjects, events, and licensing. PhD dissertation, Department of Linguistics, Massachusetts Institute of Technology, 1995.

LEVIN, BETH; RAPPAPORT HOVAV, MALKA. Unaccusativity: At the Syntax-Lexical Semantics Interface. Linguistic Inquiry Monograph 26. Cambridge, MA: MIT Press, 1995.

MARANTZ, ALEC. No Escape from Syntax: Don't Try Morphological Analysis in the Privacy of Your Own Lexicon. In: DIMITRIADIS, A.; Siegel, L.; SUREK-CLARK, C.; WILLIAMS, A. University of Pennsylvania Working Papers in Linguistics 4. Philadelphia: University of Pennsylvania, 1997. p. 201225

MINUSSI, RAFAEL DIAS. Os sabores do nome: um estudo sobre a seleção de argumentos e as nominalizações do hebraico. Tese (Doutorado em Letras) Faculdade de Filosofia, Letras e Ciências Humanas, Universidade de São Paulo. São Paulo, 2012.

MINUSSI, RAFAEL DIAS. Os nomes compostos do hebraico: uma análise morfossintática. Estudos Linguísticos, São Paulo, v. 38, n. 1, p. 259-27, 2009.

MINUSSI, RAFAEL DIAS. A relação entre Caso e definitude no hebraico: o Construct State e a marcação diferencial de objeto. Dissertação de mestrado, USP, 2008. Disponível em: http://www.teses.usp.br/teses/disponiveis/8/8139/tde30092008-152504/

NÓBREGA, VITOR AUGUSTO. Sobre raízes e domínios de interpretação: resenha de "On the Identity of Roots", de Heide Harley. ReVEL, vol. 13, n. 24 , 2015.

NOBREGA, VITOR AUGUSTO; MINUSSI, RAFAEL DIAS. O tratamento da morfologia não-concatenativa pela morfologia distribuída: o caso dos blends fonológicos. Revista Letras, v. 91, p. 158-177, 2015.

MINUSSI, RAFAEL DIAS; NOBREGA, VITOR AUGUSTO. A interface sintaxe-pragmática na formação de palavras: avaliando os pontos de acesso da Enciclopédia na arquitetura da gramática. Veredas (UFJF. Online), v. 18, p. 161184, 2014.

PINKER, STEVEN. Words and Rules. New York, NY: Harper Perennial, 1999.

PHAM, M. Idiomatic Root Merge in Modern Hebrew blends. Proceedings of the Arizona Linguistics Circle 4, Coyote Papers: Working Papers in Linguistics, v. 18, n. 1, 2011.

PFAU, ROLAND. Grammar as process: A Distributed Morphology account of spontaneous speech errors. Amsterdam: John Benjamins Publishing Company, 2009.

RAPPAPORT HOVAV, MALKA. Individuation criteria for roots. Theoretical Linguistics, v. 40, n. 3/4, p. 429-437, 2014. 
R. D. MinusSi

$\&$ I. S. BASSANI Em favor do conteúdo semântico das raízes
ROCHA, SONIA R. A ocorrência de "coisar" em Lingua Portuguesa como contribuição para a hipótese das raízes abstratas. Dissertação (Mestrado em Letras) Faculdade de Filosofia, Letras e Ciências Humanas, Universidade de São Paulo. São Paulo, 2008.

SCHER, ANA PAULA; BASSANI, INDAIÁ DE SANTANA; MINUSSI, RAFAEL DIAS. Morfologia em Morfologia Distribuída. Estudos Linguísticos e Literários, v. 47, p. 9-29, 2013.

SIDDIQI, DANIEL. Syntax within the word: economy, allomorphy, and argument selection in Distributed Morphology. [Linguistik Aktuell/Linguistics Today 138]. Amsterdan: John Benjamins, 2009.

Submetido em: 26-02-2017

Aceito em: 01-05-2017 